\title{
US, EU prepare for further biotech food dispute
}

The European Commission (EC) adopted new agriculture-related proposals on genetically modified organisms (GMOs) late in July. With the ink on those proposals barely dry, a broad coalition drawn from the US food and agriculture industries began imploring US officials to join battle against the specifics of those proposals and, more generally, to develop a wider challenge against both current and pending European Union (EU) restrictions on imports from the United States of biotechnology-derived food and agricultural products.

Following a recent pattern of confrontation rather than assuagement on matters of international dispute, top Bush administration officials appear ready to go for broke here, too, hinting that a contest over agbiotech products before the World Trade Organization (WTO; Geneva) would not be out of the question. Of course, mounting a WTO-level challenge would not be appropriate until the most recent EC proposals are actually implemented. But, as those proposals are now framed, members of the agriculture and food producer coalition find plenty to criticize.

The EC proposals contain new provisions for tracing and labeling all food and feed consisting of, containing, or produced from, GMOs (Nat. Biotechnol. 19, 795, 2001). For instance, the proposed rules call for the ability to trace such ag products through all stages of production and distribution, with the express purpose of monitoring any effects that they might have on human health and the environment. Moreover, the food-labeling proposals go beyond current standards by requiring labels for all foods produced by GMOs regardless of whether detectable DNA or protein is in those products. "Certainly there is a cost ... but what is at stake is our ability to build public confidence," says EU Environment Commissioner Margot Wallstrom, referring to the recent proposals. "European consumers will only be able to seize the opportunities provided by biotechnology if this confidence is established."

In a separate development early in September, the commission proposed to tighten labeling rules for allergens in foods. The new proposal would abolish the current rule that says producers are not obliged to indicate allergenic ingredients unless they make up $25 \%$ or more of intentionally added materials in a food product. The new rules call for noting all such ingredients that are intentionally added to foodstuffs. One major concern revolving around biotech foods is that gene splicing may inadvertently introduce novel allergens.

A proposal having to do with another type of threshold in the July GMO-related proposals is provoking criticisms from other parties to the GMO debate. In those provisions, the EC would set a threshold of $1 \%$ for the "adventitious" presence of GMOs in food and feeds, below which products would not need to carry special labels indicating their presence. Biotech critics at Greenpeace immediately blasted this provision, saying it risks "opening a hole in the dike, allowing ... unauthorized GMOs into the EU market." In calling this provision "the wrong reaction" to pressures from the US administration and industry, Greenpeace European Unit political advisor Brigid Gavin urges the EU instead to set "clear and uncompromising safety standards" for GMOs in foods and warns against "opening loopholes" that would enable industry to "continue...sneaking unwanted and dangerous GMOs into our food chain."

Meanwhile, many other July EC proposals are provoking oppositely aimed but equally blistering criticisms from the US industry coalition, whose members repeatedly-and sympathetically - made their case to toplevel Bush administration officials during the past months. "This is a major deal for the Bush administration," says one insider. "There is extensive high-level attention at the cabinet and subcabinet level. They are engaged in the debate, and looking at the WTO as a potential remedy."

Behind the scenes, members of the administration are working closely with members of an industry and producer coalition that includes more than two dozen associations of farmers, specialty crop producers, processors, grain handlers, grocery manufacturers, and food exporters. In a recent letter from the coalition addressed to Secretary of Agriculture Ann Veneman, for example, coalition mem- bers called the proposed EU food labeling regulations "onerous, unworkable, and internally inconsistent" and said that, if implemented, they would be a "serious trade impediment" for essentially all foods produced with biotechnology-derived materials.

These critics also specifically object to the proposed GMO “traceability" provisions, saying they fall short of meeting the EC's stated three major goals of facilitating product recall, monitoring potential human health or environmental effects, and verifying labeling claims. Whether developed through documentation procedures or by direct testing, heeding these provisions would pose "serious questions of cost, risk, and feasibility," these critics assert. They also consider the proposed threshold provisions "not sufficient to provide ...confidence that [their implementation] will allow corn exports to ... resume." And they object to other provisions that extend the EU approval process to animal feeds, saying this expansion further "threatens hundreds of millions of dollars of US feed exports."

Underlying this forceful critique of the July proposals is smoldering unhappiness among US food producers over what amounts to a three-year moratorium on approving US biotechnology-derived products for import into EU markets. Although some of the affected products have moved through the premarket scientific review phase of approvals, critics say, political decisions about them are still pending - a situation that now costs US food producers at least $\$ 200$ million per year and could go up, particularly because of the new provisions that extend restrictions to food oils and to animal feeds. "The new proposals could escalate tensions between the US and Europe," says a critic who represents US food producers. "They can't be challenged at the WTO until they're implemented, but we are doing the analysis now and using the WTO threat as a way of motivating the Europeans."

Jeffrey L Fox, Washington, DC

\section{Bayer lapse exposes pharma's vulnerability}

The voluntary withdrawal of Bayer's (Leverkusen, Germany) cholesterol-lowering drug cerivastatin (Baycol/LipoBay) at the beginning of August was clearly a major setback for the company, but the implications of the move sound warnings for the pharmaceutical industry outside Leverkusen. In particular, they may have repercussions for those drug companies that have merely stood still too long and are now being left behind in R\&D and in marketing by mega-mergers.

Bayer withdrew the drug as a result of post-marketing surveys (phase IV) that found an increased occurrence of the muscle-wasting disease rhabdomyolysis in patients given the drug. The US Food and Drug Administration (Rockville, MD) sent out a "Dear Healthcare Professional" letter on August 8 announcing that Bayer had withdrawn the drug. It pointed out that rhabdomyolysis was an adverse effect of all statins, the class of compounds to which cerivastatin belongs, but that there was "an increased reporting rate of rhabdomyolysis with Baycol relative to other statins." This 